\title{
Retrospective review of epidemic viral pneumonia cases in Turkey: A multicenter study
}

\author{
MUSTAFA ÇÖRTÜK $^{1}$, MURAT ACAT ${ }^{1}$, ONUR YAZICI $^{2}$, ZEHRA YASAR $^{3}$, \\ KEMAL KIRAZ $^{4}$, SENA YAPICIOGLU ATAMAN ${ }^{5}$, ELIF TANRIVERDI $^{6}$, BURCAK ZITOUNI ${ }^{1}$, \\ CENK KIRAKLI $^{5}$, OZLEM EDIBOGLU ${ }^{5}$, FEVZIYE TUKSAVUL ${ }^{5}$, ADEM DIRICAN $^{7}$, \\ HALE KEFELI CELIK $^{8}$, SEVKET OZKAYA $^{9}$ and ERDOGAN CETINKAYA ${ }^{6}$ \\ ${ }^{1}$ Department of Chest Diseases, Karabük University Faculty of Medicine, 78200 Karabük; \\ ${ }^{2}$ Department of Chest Diseases, Adnan Menderes University Faculty of Medicine, 09010 Aydın; \\ ${ }^{3}$ Department of Chest Diseases, Abant İzzet Baysal University Faculty of Medicine, 14280 Bolu; \\ ${ }^{4}$ Department of Chest Diseases, Antalya Atatürk State Hospital, 07040 Antalya; \\ ${ }^{5}$ Department of Chest Diseases, Izmir Dr Suat Seren Thoracic Diseases and Surgery Training and Research Hospital, \\ 35110 İzmir; ${ }^{6}$ Department of Chest Diseases, Yedikule Chest Diseases and Thoracic Surgery Training and \\ Research Hospital, 34020 İstanbul; ${ }^{7}$ Department of Pulmonary Medicine, Samsun Medical Park Hospital, 55200 Samsun; \\ ${ }^{8}$ Department of Anesthesiology and Intensive Care Unit, Samsun Training and Research Hospital, 55100 Samsun; \\ ${ }^{9}$ Department of Pulmonary Medicine, Bahcesehir University Faculty of Medicine, 34720 Istanbul, Turkey
}

Received September 26, 2016; Accepted December 6, 2016

DOI: $10.3892 / \mathrm{etm} .2017 .4153$

\begin{abstract}
Influenza A (H1N1) caused its first pandemic in 2009 in USA and Mexico. Since then, clinicians have exercised great care in order to make an early diagnosis of viral pneumonias. This is due in part to pandemic influenza A infection having greater impact on populations $<65$ years old than other viral strains, including seasonal influenza. Chest radiographies of those affected displayed a rapid progression of patchy infiltrates, and a large proportion of individuals required admission to intensive care units (ICU). Despite efforts, patients infected with the virus had a high mortality rate. The present multicenter study aimed to retrospectively evaluate the clinical, demographic and prognostic characteristics of patients diagnosed with epidemic viral pneumonia in Turkey. A total of 92 patients were included in the study. The Student's $t$-test and Chi-square tests were performed to analyze quantitative data, assuming a normal distribution, and to analyze qualitative data, respectively. Stepwise logistic regression was used to evaluate the effects of demographic variables and laboratory values on the
\end{abstract}

Correspondence to: Dr Mustafa Çörtük, Department of Chest Diseases, Karabük University Faculty of Medicine, Şirinevler, Alpaslan Caddesi 1, 78200 Karabük, Turkey

E-mail:mcortuk@yahoo.com

Key words: pandemic, influenza, human, H1N1 virus, pneumonia, viral, radiology, respiratory insufficiency, intensive care units, smoking virus mortality rate. The male/female ratio was $42 / 50$ and the mean age was $48.74 \pm 16.65$ years. A total of $69(75 \%)$ patients were unvaccinated against influenza. The most common symptoms were cough $(87 \%)$ and fever (63\%). Chest computed tomography showed peripheral patchy areas of the lungs of ground glass density in 38 patients (41.3\%). A total of $22(59.4 \%)$ patients had H1N1, $5(12.5 \%)$ patients had influenza B, and $38(41.3 \%)$ patients met the criteria for admission to the ICU. Of these patients, 20 (52.63\%) were monitored with a mechanical ventilator, with a noninvasive ventilator being adequate for $10(26.32 \%)$ of patients. The length of stay in the ICU was $6.45 \pm 5.97$ days and the duration of mechanical ventilation was $5.06 \pm 4.69$ days. A total of 12 (13.04\%) patients in the ICU succumbed. Logistic regression analysis revealed that among the parameters possibly associated with mortality, being an active smoker increased the risk of mortality 7.08 -fold compared to other groups $(\mathrm{P}=0.005)$. In conclusion, viral pneumonia remains a significant health problem during the winter period. Considering the high number of ICU admissions and high rate of mortality for patients in the present study, earlier initiation of antiviral therapy is necessary. Active smoking increased mortality in viral pneumonia.

\section{Introduction}

Community-acquired pneumonia (CAP) is a leading disease associated with a high mortality and requiring hospitalization $(1,2)$. In the United States, 4 million people are diagnosed with CAP annually, with $\sim 600,000$ of these patients requiring hospitalization (3). In Turkey, according to the 2014 health statistics by the Turkish Ministry of Health, pneumonia accounts for $2.6 \%$ of mortality cases (4). 
It is not always possible to establish the disease etiology for patients with pneumonia (5). In addition, although the equipment required to identify the etiologic agent is available, isolation of the agent may take up to seven days (6). A review of the CAP literature in Turkey shows an identification rate of $21-62.8 \%$ (5). Holter et al (7) and Qu et al (8) reported that viral agent was present in $\sim 1 / 3$ of all pneumonias in Norway and China, respectively. In patients with CAP, a delay $>4-8 \mathrm{~h}$ in treatment results in an increased mortality rate (9). Pneumonia is initially treated with empiric therapy, since isolation of the agent is challenging and time-consuming. Two newly published studies have shown that viruses in CAP patients were detected as causative agents in $34 \%$ and $27.5 \%$, respectively. $(7,8)$. In these studies, influenza and human rhinovirus were the most common causative agents. Other agents included parainfluenza viruses, respiratory syncytial virus, metapneumovirus, enterovirus and adenovirus $(7,8)$.

A new strain of Influenza A virus caused an outbreak of human infection in April 2009 in the USA and Mexico, and spread rapidly to other regions. This strain was classified as Influenza A H1N1 (H1N1) (10). Since 2009, this novel virus has been the most prevalent viral pneumonia agent among the respiratory viruses (7). The influenza A H1N1 infection exhibits a greater impact on populations $<65$ years old than other seasonal influenza viruses (10). Pandemic H1N1 is primarily a mild, self-limiting upper respiratory tract illness, but unlike seasonal influenza, H1N1 leads to a more severe infection and high mortality rate in young adults (11). It was reported that $2-5 \%$ of confirmed cases in the USA and Canada, and $6 \%$ of cases in Mexico required hospitalization (12). The majority of hospitalized patients had underlying conditions such as cardiovascular disease, respiratory diseases including asthma and chronic obstructive pulmonary disease, auto-immune disorders, obesity, diabetes or cancer (12). In addition, secondary bacterial infections may be accompained by influenza pneumonia (7). Treatment with oseltamivir in H1N1 infections should be initiated within the first 48 hours (13). Therefore, it is necessary to ensure early diagnosis of viral pneumonias.

The present multicenter study retrospectively examined the clinical, demographic and prognostic characteristics of patients diagnosed with epidemic viral pneumonia in Turkey.

\section{Patients and methods}

Patients and viral pneumonia diagnosis. A total of 92 patients were included in the study. The male/female ratio was $42 / 50$, and the mean age was $48.74 \pm 16.65$ years. Patients were from 11 individual secondary and tertiary care hospitals located in various regions of Turkey and the study was performed retrospectively from January 2015 to April 2015. The patients had all been previously diagnosed with viral pneumonia. The patient files were retrospectively reviewed and included in the study. Viral pneumonia was diagnosed according to clinical and radiological examination results, and the exclusion of alternative causes. To confirm the diagnosis of viral pneumonia, nasopharyngeal, oropharyngeal and nasal swab specimens were placed into Virocult transport media (Medical Wire \& Equipment, Wiltshire, UK), and transferred to the Virology Laboratory of the Ankara Refik Saydam
Hygiene Institute (Ankara, Turkey) in accordance with the cold chain principles (14), and were evaluated using the quantitative polymerase chain reaction (qPCR) method assay as recommended by the World Health Organization (15). Following appropriate preparations, accepted laboratory samples were tested with PCR to detect the presence of influenza A/influenza $\mathrm{B}$ via targeting the conservative gene region of the influenza virus. A second $\mathrm{PCR}$ reaction was carried out using $\mathrm{H} 1, \mathrm{H} 3$ and $\mathrm{H} 5$ primers to identify the subtype of the influenza virus present in the samples. Based on the full genomic sequence of the recently-identified H1N1 virus, incoming samples were sequenced. Therefore, typing and genetic characterization of virus was provided.

All patients were treated with $150 \mathrm{mg}$ /day of the antiviral therapeutic oseltamivir. Secondary bacterial infections may be accompained by influenza pneumonia; therefore patients additionally received intravenous fluoroquinolones or clarithromycin (1,000 mg/day), in combination with intravenous $\beta$-lactam antibiotics.

Monitoring of viral pneumonia. The symptoms, medical history, radiological examination, hemogram levels, C-reactive protein (CRP) level (normal range: $0-5 \mathrm{mg} / \mathrm{l}$ ) and biochemical parameters (such as sedimentation, urea, creatinine, aspartate aminotransferase, alanine aminotransferase, lactate dehydrogenase, creatine kinase) of the patients were recorded. Arterial blood gas values for those who required intensive care admission were also recorded. Furthermore, the following were obtained from the patient files: Relevant information from the day of presentation after the onset of symptoms, monitoring parameters [such as arterial blood pressure, pulse rate, fever, and days spent in the intensive care unit (ICU)] were recorded in the clinic and/or ICU, and the treatment administered following disease diagnosis.

Statistical analysis. Data analysis was performed using the Minitab 14 statistical software (Minitab, Inc., State College, PA, USA). Descriptive statistics were performed to analyze patient characteristics (Table I). The Student's $t$-test and Chi-square test were performed to analyze quantitative data, assuming a normal distribution, and to analyze qualitative data, respectively. $\mathrm{P}<0.05$ was considered to be statistically significant. Prognosis was used as an outcome (response variable) to establish a binary logistic regression model, with ' 1 ' corresponding to alive, and ' 0 ' corresponding to mortality. Initially, the complete set of demographic variables and laboratory values that were potentially associated with mortality were included in the model. Following this, a backward-elimination approach was performed within a multiple explanatory variable logistic regression model in order to evaluate the model for potential confounding effects. In this model, the factors/covariates were removed individually in decreasing order of P-value until the remaining factors had a two-sided $\mathrm{P}$ value $<0.05$. Following this, the Hosmer-Lemeshow test was performed to determine the goodness-of-fit.

The study was approved by the Ethics Board of the Abant İzzet Baysal University (Bolu, Turkey). The requirement for informed consent was waived by the Ethics Board due to the study's retrospective design. 
Table I. Demographic and laboratory characteristics of patients.

\begin{tabular}{lll}
\hline Variable & $\mathrm{n}$
\end{tabular}

Age (mean $\pm \mathrm{SD})$, year

Male/female

$48.7 \pm 16.6$
$42 / 50$

Smoking status

Non-smoker

47

Smoker

18

Ex-smoker

Past contact with upper

respiratory viral infections

Influenza vaccination

No

Yes

Arterial blood gas (median)

$\mathrm{pH}$

$\mathrm{PaO}_{2}(\mathrm{mmHg})$

$\mathrm{PaCO}_{2}(\mathrm{mmHg})$

$\mathrm{SaO}_{2}(\%)$

Laboratory values (median)

Leukocytes $\left(/ \mathrm{mm}^{3}\right)$

6,484

Lymphocytes $\left(/ \mathrm{mm}^{3}\right)$

1,000

Neutrophils $\left(/ \mathrm{mm}^{3}\right)$

4,507

Platelets $\left(/ \mathrm{mm}^{3}\right)$

184,500

C-reactive protein $(\mathrm{mg} / \mathrm{l})$

20.3

Sedimentation $(\mathrm{mm} / \mathrm{h})$

35

Urea (mg/dl)

Creatinine (mg/dl)

0.88

Aspartate aminotransferase (IU/l)

Alanine aminotransferase (IU/1)

Lactate dehydrogenase (IU/1)

401.5

Creatine kinase (IU/1)

Chest X-ray

Consolidation

Bilateral

Unilateral

Pleural effusion

Chest tomography

Consolidation

Bilateral

Unilateral

Pleural effusion

Virology

H1N1 positivity

Influenza positivity

Negative

\section{Results}

Patient characteristics and symptoms. Of the 92 patients that were included in the present study, 69 (75\%) patients were unvaccinated against influenza. The demographic characteristics, main laboratory results and radiological findings of the patients are outlined in Table I. The most prevalent symptoms were a cough (87\%) and a fever (63\%). The duration between the onset of symptoms and presentation to the hospital was $5.51 \pm 3.27$ days, and 18 patients (19.6\%) had a history of contact with individuals complaining of upper respiratory tract viral infections. The prevalence of symptoms is depicted in Table II. No additional disorders were found in $56.5 \%$ of patients. The prevalence of comorbidities are shown in Table II.

Clinical indications of pneumonia. Chest radiographies revealed bilateral patchy pneumonic infiltrates in $69.6 \%$ of patients. Chest computed tomography (CT) identified peripheral multiple patchy areas of ground glass density in 38 patients $(41.3 \%)$. Bilateral alveolar-interstitial consolidations and ground-glass opacities were observed in five patients by chest X-ray and CT imaging (Figs. 1-5). From the laboratory findings, leukocyte count was found to be within the normal range, $>10,000 / \mathrm{mm}^{3}$, in 54 patients $(58.7 \%)$. The lymphocyte count was found to be below the normal limit, at a median value of $1,000 / \mathrm{mm}^{3}$, in 34 patients $(37 \%)$. The laboratory data are detailed in Table I.

The throat and nasal swab specimens of 37 patients with clinical and radiological findings suggestive of viral pneumonia were sent to the laboratory. Treatment was initiated on the same day. A total of $22(59.4 \%)$ of these patients had H1N1, and $5(12.5 \%)$ patients had influenza B. Patients with suspected viral pneumonia were administered the antiviral drug oseltamivir, on a dose of $150 \mathrm{mg} /$ day, and monitored accordingly.

Outcomes of patients admitted to the ICU. Of the 92 patients in total, $38(41.3 \%)$ patients met the criteria for admission to the ICU. Of these patients, $20(52.63 \%)$ were monitored with a mechanical ventilator, with a noninvasive mechanical ventilator (NIMV) being adequate for $10(26.32 \%)$ of the patients. A smaller group of $8(8.7 \%)$ patients were monitored 69.6 with NIMV during weaning from mechanical ventilation. 25.0 The length of stay in the ICU was 6.45 \pm 5.97 days (1-30 days), and the duration of mechanical ventilation (MV) was $5.06 \pm 4.69$ days (1-18 days). A total of 12 (13.04\%) patients did not survive treatment. Logistic regression analysis indicated that among the parameters potentially associated
79.2

20.8

59.4

27.1
$\mathrm{SD}$, standard deviation; $\mathrm{PaO}_{2}$, partial arterial oxygen pressure; $\mathrm{PaCO}_{2}$, partial arterial carbon dioxide pressure; $\mathrm{SaO}_{2}$, arterial oxygen saturation. with mortality, current smoking increased the mortality risk 7.08-fold compared with non-smokers and ex-smokers $(95 \%$ confidence interval: 1.81-27.67) $(\mathrm{P}=0.005)$. No significant relationship was found between mortality and other parameters, including age, gender, comorbid diseases, platelet count, lactate dehydrogenase ( $\mathrm{LDH}$ ) level, arterial blood oxygen level at the time of presentation and creatine kinase (CK).

\section{Discussion}

The present study demonstrated that the majority of patients diagnosed with viral pneumonia were middle-aged 
individuals presenting with major symptoms of a cough, fever and shortness of breath. The patients displayed a rapid progression of patchy infiltrates in their chest radiographies and a large proportion required admission to the ICU. A total of $38(41.3 \%)$ patients were monitored at the ICU, and 20 (52.63\%) required MV. The rate of mortality was $13.04 \%$. Active smoking caused a 7.08 -fold increase in the mortality risk.

In the present study, the mean age was $48.74 \pm 16.65$ years, with no significant difference in gender. A past study comparing patients with bacterial CAP and viral pneumonias found the mean age to be $60.0 \pm 20.2$ years for bacterial CAP patients vs. $49.7 \pm 18.7$ years for viral pneumonia patients (16). In a general study of patients with CAP, the mean age was 66 years, with a range of 52-78 years (7). Another study found that $90.3 \%$ of patients with H1N1 were younger than 65 years (17). In the present study, the mean age was found to be lower for viral pneumonia compared to that recorded previously for bacterial pneumonia $(5,16)$. However, the present results are consistent with the previously recorded mean ages of patients with viral pneumonia $(16,18)$.

A study including 1,088 cases performed in 2009 during the H1N1 pandemic reported that the clinical status of patients deteriorated rapidly; $31 \%$ required intensive care, mortality was higher in those $>50$ years-old, overall mortality was $11 \%$ and the rate of comorbidity was $68 \%$ (19). Similarly, Gürgün et al reported that $25 \%$ of patients diagnosed with influenza pneumonia required intensive care (16), while Almirall et al found that the rate of ICU admissions was $7 \%$ in patients with bacterial CAP vs. $19.3 \%$ in patients with viral CAP (20). Furthermore, Rello et al reported an ICU admission rate of $62.5 \%$ in H1N1 pneumonia (21). For the patients of the present study, the rate of ICU admission was $41.3 \%$. This higher rate relative to that documented for bacterial pneumonia suggests that patients with suspected viral pneumonia may require closer monitoring (5).

An analysis of several demographic and laboratory phenotypes (including age, gender, CRP level, sedimentation, urea, creatinine, aspartate aminotransferase, alanine aminotransferase, lactate dehydrogenase and creatine kinase) associated with mortality indicated that active smoking increased the mortality risk 7.08 -fold. Previously published studies on CAP have revealed that $72 \%$ of pneumonia cases requiring intensive care were predisposed by smoking (22). Similarly, smoking has been found to be a risk factor in patients requiring admission to the ICU for viral pneumonia (23). Cigarette smoke disrupts the pulmonary defense mechanism by reducing mucociliary clearance (24). This deterioration in the defence mechanism may be associated with the increased rate of mortality with pneumonia in current smokers. Although it is established that mortality is higher in patients admitted to the ICU, a direct association between active smoking and mortality in viral pneumonia remains to established. Previous analysis of the radiological imaging methods indicated that bilateral involvement was greater in viral pneumonias (25), while other studies found that radiological presentation varies substantially, and thus, has no predictive value in differential diagnosis (26). Similar to the results by Shiley et al (25), present results of the chest radiography and chest $\mathrm{CT}$ imaging revealed bilateral
Table II. Distribution of symptoms and comorbid diseases in patients.

\begin{tabular}{|c|c|c|}
\hline Variable & $\mathrm{n}$ & $\%$ \\
\hline \multicolumn{3}{|l|}{ Symptoms } \\
\hline Cough & 80 & 87.0 \\
\hline Fever & 58 & 63.0 \\
\hline Dyspnea & 54 & 58.7 \\
\hline Malaise & 30 & 32.6 \\
\hline Myalgia & 16 & 17.8 \\
\hline Headache & 15 & 16.3 \\
\hline Gastrointestinal $^{\mathrm{a}}$ & 7 & 7.6 \\
\hline Upper airway $^{\mathrm{b}}$ & 7 & 7.6 \\
\hline Chest pain & 6 & 6.5 \\
\hline Hemoptysis & 2 & 2.2 \\
\hline Hoarseness & 1 & 1.1 \\
\hline \multicolumn{3}{|l|}{ Comorbidities } \\
\hline None & 52 & 56.5 \\
\hline Hypertension & 16 & 17.4 \\
\hline Chronic obstructive pulmonary disease & 14 & 15.2 \\
\hline Diabetes mellitus & 11 & 12.0 \\
\hline Asthma & 6 & 6.5 \\
\hline Coronary artery disease & 5 & 5.4 \\
\hline Malignancy & 2 & 2.2 \\
\hline Cerebrovascular disease & 1 & 1.1 \\
\hline
\end{tabular}

${ }^{\mathrm{a}}$ Nausea, vomiting, diarrhea, ${ }^{\mathrm{b}}$ Sore throat, cold.

pneumonic infiltrates in 69.6 and $79.2 \%$ of patients, respectively.

The current study found that $69(75 \%)$ patients were unvaccinated against influenza. This may be due to the proportion of young adults included in the patient group, or that only $26.09 \%$ of cases exhibited comorbidities. As viral pneumonias are thought to progress rapidly following the onset of symptoms (21), and the present study found a mortality rate of $13.04 \%$, these results suggest that influenza vaccination should not be overlooked by individuals who have no contraindications for vaccination. In the present study, 1 out of 12 of the patients who did not survive were vaccinated against influenza.

Similar to previous studies, the current study found that the majority (59.4\%) of viral swab specimens taken from patients with suspected viral pneumonia were positive for influenza A $(7,8)$. The patients from whom specimens where not requested consisted of those who had suspected viral pneumonia based on clinical, radiological and laboratory findings, however, lacked the growth of any other microorganisms. In clinical practice in Turkey, swab specimens from patients who are suspected to have viral pneumonia, are analysed only during the 'influenza season' (i.e., December-March). When cases of influenze are less prevalent, diagnoses are made according to clinical and radiological findings. Nevertheless, an association between early antiviral treatment and better survival has been demonstrated by previous studies $(19,27)$. In the present 

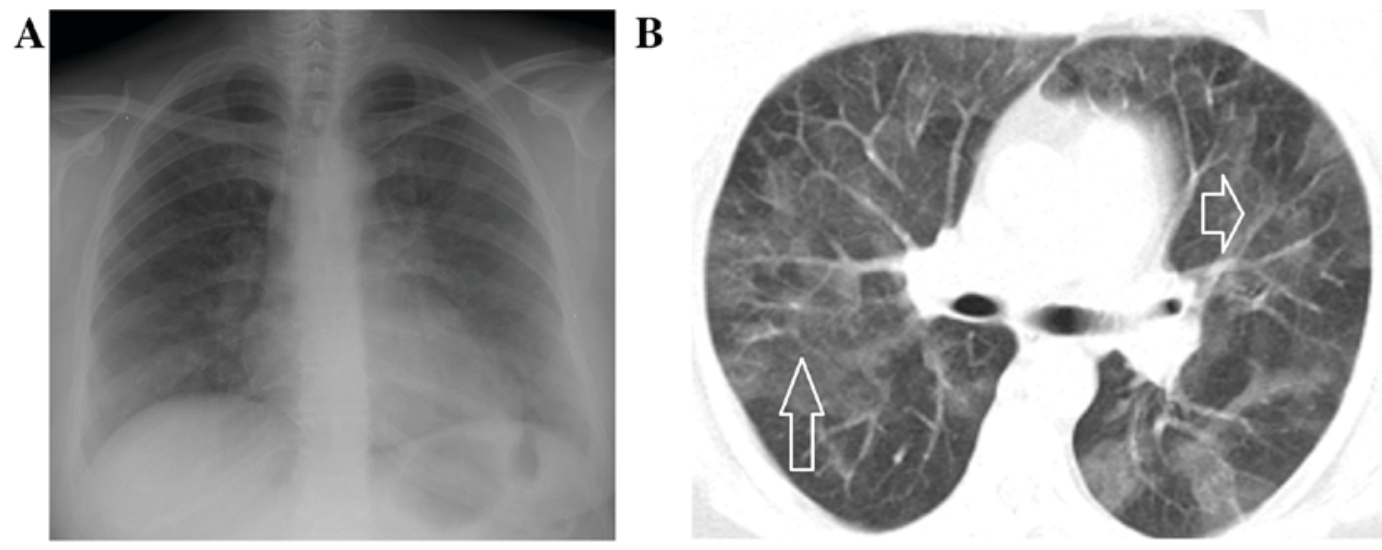

Figure 1. Influenza A (H1N1)-positive viral pneumonia. Image shows a 49-year-old woman admitted to hospital with complaints of a cough and fever. (A) The posteroanterior chest X-ray and (B) thoracic computed tomography scan displayed bilateral patchy ground-glass opacities (arrows).
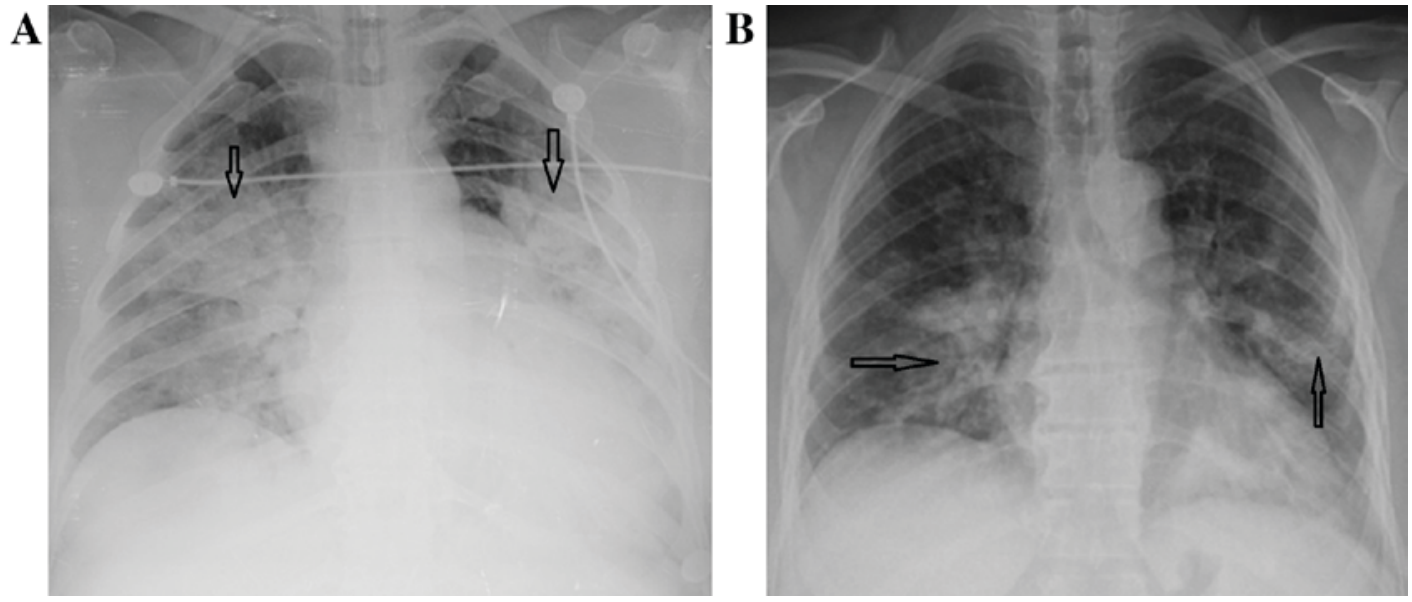

Figure 2. Influenza A (H1N1)-positive viral pneumonia. Image shows a 43-year-old man admitted to the intensive care unit due to acute respiratory failure. (A) Bilateral alveolar-interstitial consolidations and ground-glass opacities (arrows) were observed by chest X-ray. (B) One month later, healing with fibrosis (arrows) was observed by chest X-ray.
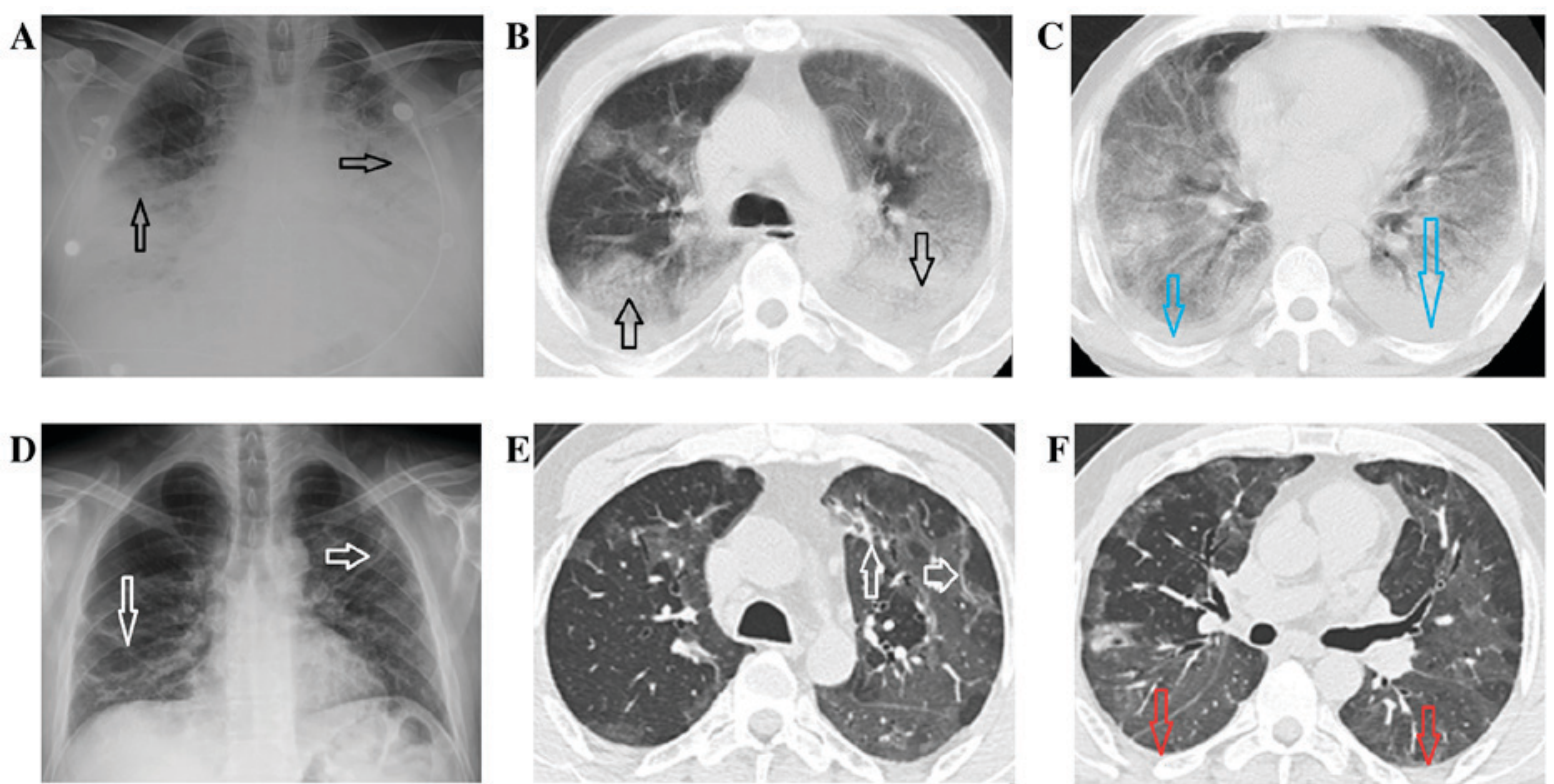

Figure 3. Influenza A (H1N1)-positive viral pneumonia. Image shows a 43 year-old man admitted to the intensive care unit due to acute respiratory failure. Bilateral alveolar-interstitial consolidations and ground-glass opacities (black arrows) were observed by (A) chest X-ray and (B) chest computed tomography imaging. (C) Bilateral minimally pleural fluid was also observed on chest computed tomography (blue arrows). One month later, (D and E) healing with fibrosis (white arrow) was observed and (F) pleural fluid had disappeared (red arrow). 

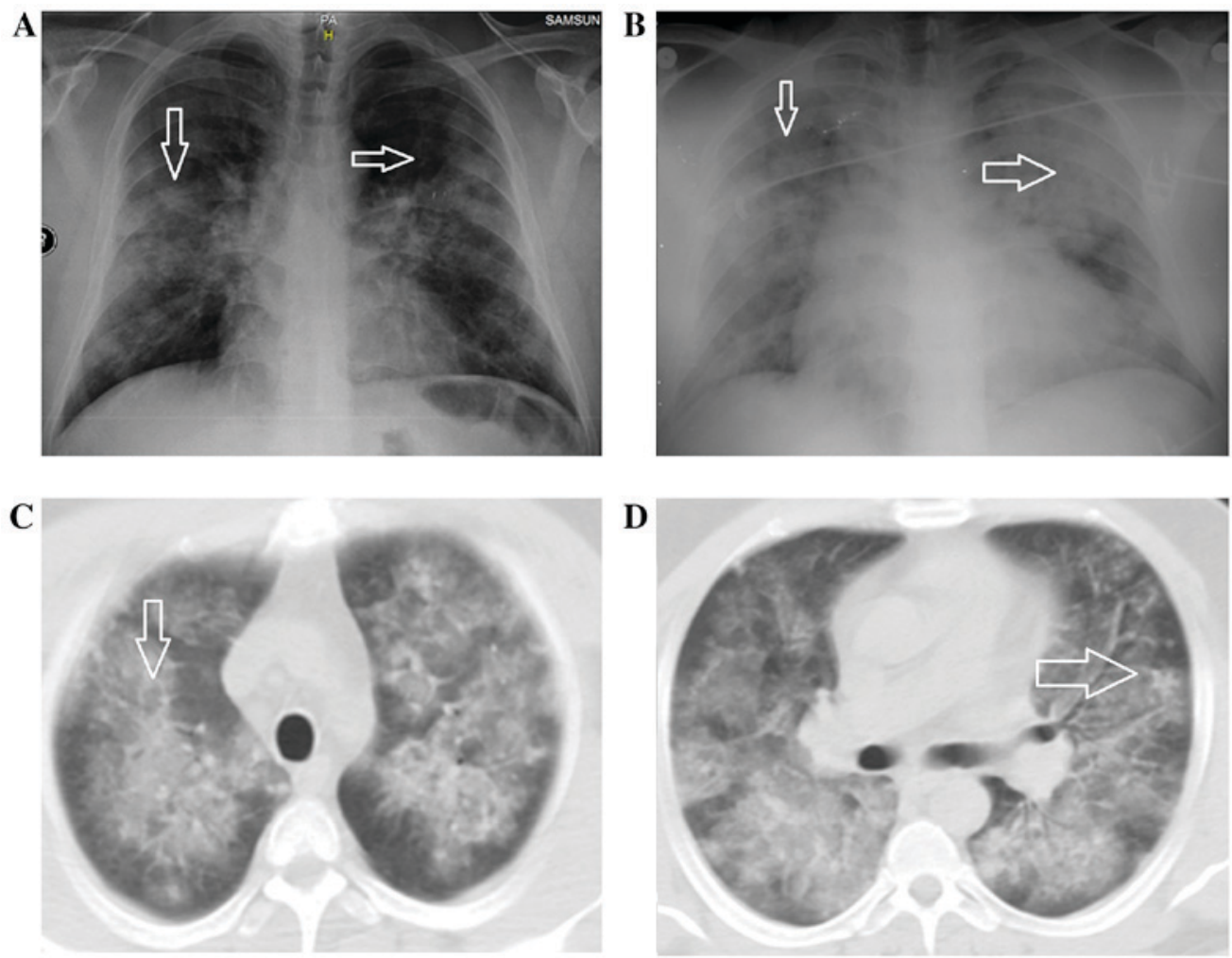

Figure 4. Influenza A (H1N1)-positive viral pneumonia. Image shows a 38-year-old man presented with a cough, dyspnea and fever. (A and B) The posteroanterior chest X-ray revealed rapidly progressing bilateral consolidation (arrows), despite treatment with antibiotics. (C and D) Bilateral alveolar-interstitial consolidations and ground-glass opacities (arrows) were observed by chest computed tomography imaging.
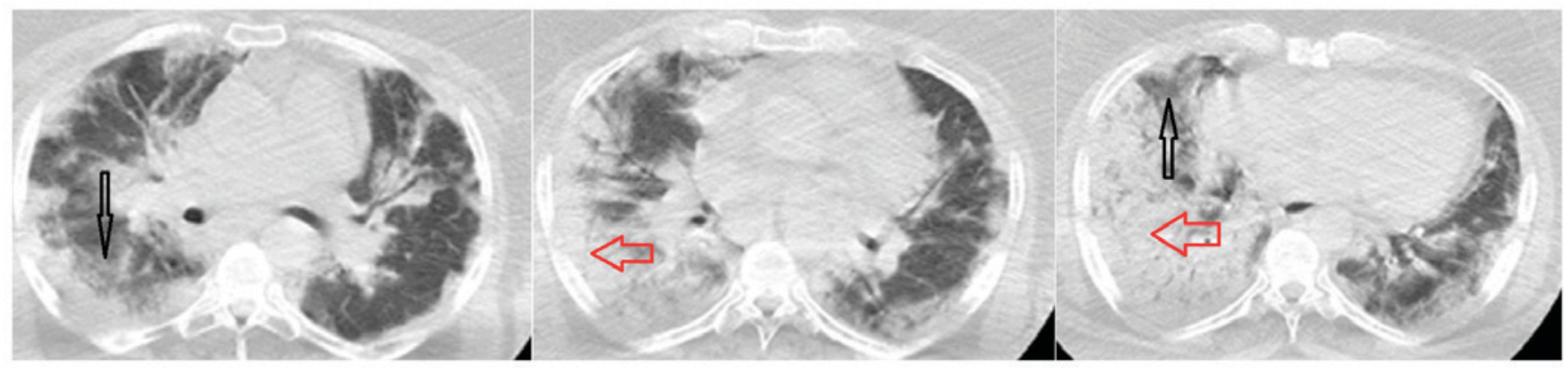

Figure 5. Influenza A (H1N1)-positive viral pneumonia. Image shows a 55-year-old woman admitted to hospital with complaints of a cough, dyspnea and fever. Chest computed tomography imaging displayed bilateral alveolar consolidations (red arrows) and ground-glass opacities (black arrows).

study, patients were treated with oseltamivir. Secondary bacterial infections may be accompained by influenza pneumonia $(7,28)$; therefore, patients additionally received fluoroquinolone or clarithromycin, in combination with intravenous $\beta$-lactam antibiotics.

The current study had a number of limitations. In January 2015 , the cases of viral pneumonias were considered to be sporadic and not at an epidemic level. Therefore, specimens were not obtained from each patient to identify the strain types. By contrast, when increasing numbers of cases were reported by multiple centers, particularly in February and March 2015, specimens were collected from the patients to confirm the diagnosis of viral pneumonia. The present study was performed retrospectively and was multicentric; as such, some laboratory results could not be obtained from all patients.
In conclusion, viral pneumonia remains a major health problem during the winter period. In affected patients, the $\mathrm{H} 1 \mathrm{~N} 1$ virus is a potential etiologic agent. Therefore, H1N1 should be considered, particularly in patients presenting with symptoms of pneumonia. These include fever, shortness of breath and muscle pain during the influenza season, coupled with clinical characteristics, including high levels of CRP, $\mathrm{LDH}$ and $\mathrm{CK}$, and radiological evidence of bilateral pneumonic infiltrates that progress rapidly. Smoking habits should be particularly questioned, due to findings of an association between active smoking and increased mortality. As viral pneumonia is associated with high mortality and the need for ICU admission, antiviral treatment should be rapidly initiated upon clinical suspicion of the disease. However, there is still no method to quickly isolate the pneumonia agent. Further research is required to elucidate the role of active 
smoking on pneumonia mortality. Additionally, further studies should be performed to identify a method for rapid and definite pneumonia agent isolation.

\section{References}

1. Welte T, Torres A and Nathwani D: Clinical and economic burden of community-acquired pneumonia among adults in Europe. Thorax 67: 71-79, 2012

2. Mandell LA, Wunderink RG, Anzueto A, Bartlett JG, Campbell GD, Dean NC, Dowell SF, File TM Jr, Musher DM, Niederman MS, et al: Infectious diseases society of America/American thoracic society consensus guidelines on the management of community-acquired pneumonia in adults. Clin Infect Dis 44: 27-72, 2007

3. Fine MJ, Auble TE, Yealy DM, Hanusa BH, Weissfeld LA, Singer DE, Coley CM, Marrie TJ and Kapoor WN: A prediction rule to identify low-risk patients with community-acquired pneumonia. N Engl J Med 336: 243-250, 1997.

4. Türkiye istatistik kurumu. www.tuik.gov.tr. Accessed March 16, 2016

5. Ozlü T, Bülbül Y and Ozsu S: Community-acquired pneumonia based on the Turkish national data. Tuberk Toraks 55: 191-212, 2007 (In Turkish)

6. Public Health Institution of Turkey: Field Guide for Laboratory Diagnosis of Contagious Diseases. http://mikrobiyoloji.thsk saglik.gov.tr/ums/B/Bakteriyel\%20pnomoniler.pdf. Accessed December 21, 2016.

7. Holter JC, Müller F, Bjørang O, Samdal HH, Marthinsen JB, Jenum PA, Ueland T, Frøland SS, Aukrust P, Husebye E, et al: Etiology of community-acquired pneumonia and diagnostic yields of microbiological methods: A 3-year prospective study in Norway. BMC Infect Dis 15: 64, 2015.

8. Qu JX, Gu L, Pu ZH, Yu XM, Liu YM, Li R, Wang YM, Cao B and Wang C; Beijing Network for Adult Community-Acquired Pneumonia (BNACAP): Viral etiology of community-acquired pneumonia among adolescents and adults with mild or moderate severity and its relation to age and severity. BMC Infect Dis 15: 89, 2015.

9. Tang CM and Macfarlane JT: Early management of younger adults dying of community acquired pneumonia. Respir Med 87: 289-294, 1993.

10. Gómez-Gómez A, Magaña-Aquino M, Garcia-Sepúlveda C, Ochoa-Pèrez UR, Falcón-Escobedo R, Comas-García A, Aranda-Romo S, Contreras-Treviño HI, Jimenéz-Rico PV, Banda-Barbosa MA, et al: Severe pneumonia associated with pandemic (H1N1) 2009 outbreak, San Luis Potosi, Mexico. Emerg Infect Dis 16: 27-34, 2010.

11. Sertogullarindan B, Ozbay B, Gunini H, Sunnetcioglu A, Arisoy A, Bilgin HM, Mermit Cilingir B, Duran M, Yildiz H, Ekin S and Baran A: Clinical and prognostic features of patients with pandemic 2009 influenza A (H1N1) virus in the intensive care unit. Afr Health Sci 11: 163-170, 2011.

12. Girard MP, Tam JS, Assossou OM and Kieny MP: The 2009 A (H1N1) influenza virus pandemic: A review. Vaccine 28: 4895-4902, 2010.

13. Fiore AE, Shay DK, Haber P, Iskander JK, Uyeki TM, Mootrey G, Bresee JS and Cox NJ; Advisory Committee on Immunization Practices (ACIP), Centers for Disease Control and Prevention (CDC): Prevention and control of influenza. Recommendations of the advisory committee on immunization practices (ACIP), 2007. MMWR Recomm Rep 56 (RR-6): 1-54, 2007.
14. Wang X, Zoueva O, Zhao J, Ye Z and Hewlett I: Stability and infectivity of novel pandemic influenza $A$ (H1N1) virus in blood-derived matrices under different storage conditions. BMC Infect Dis 11: 354, 2011.

15. Jain S, Kamimoto L, Bramley AM, Schmitz AM, Benoit SR, Louie J, Sugerman DE, Druckenmiller JK, Ritger KA, Chugh R, et al: Hospitalized patients with 2009 H1N1 influenza in the United States, April-June 2009. N Engl J Med 361: 1935-1944, 2009.

16. Gürgün A, Bacakoğlu F, Başoğlu OK, Taşbakan MS, Pullukçu H and Sayiner A: Comparison of the patients with pandemic (H1N1) influenza A virus pneumonia and community-acquired pneumonia. Tuberk Toraks 58: 357-365, 2010 (In Turkish).

17. Bakir M: Pandemic influenza situation update in Turkey. J Infect Dev Ctries 4: 124-125, 2010.

18. Duru S, Köker Y, Uyanusta Ç, Şencan N, Altaş B, Albayrak N and Ardıç S: Clinical analysis in influenza A (H1N1) virus patients. Turkish Thoracic J 13: 45-49, 2012.

19. Louie JK, Acosta M, Winter K, Jean C, Gavali S, Schechter R, Vugia D, Harriman K, Matyas B, Glaser CA, et al: Factors associated with death or hospitalization due to pandemic 2009 influenza $\mathrm{A}(\mathrm{H} 1 \mathrm{~N} 1)$ infection in California. JAMA 302: 1896-1902, 2009.

20. Almirall J, Bolíbar I, Vidal J, Sauca G, Coll P, Niklasson B, Bartolomé $M$ and Balanzó X: Epidemiology of community-acquired pneumonia in adults: A population-based study. Eur Respir J 15: 757-763, 2000.

21. Rello J, Rodriguez A, Ibañez P, Socias L, Cebrian J, Marques A, Guerrero J, Ruiz-Santana S, Marquez E, Del Nogal-Saez F, et al: Intensive care adult patients with severe respiratory failure caused by Influenza A (H1N1)v in Spain. Crit Care 13: R148, 2009.

22. Ediger D, Uzaslan EK, Yüksel EG, Coşkun F and Ege E, Karadaş M and Gözü RO: Evaluation of pneumonia cases in intensive care unit. Turkiye Klinikleri Archives Lung 6: 111-114, 2005.

23. Kumar A, Zarychanski R, Pinto R, Cook DJ, Marshall J, Lacroix J, Stelfox T, Bagshaw S, Choong K, Lamontagne F, et al: Critically ill patients with 2009 influenza $\mathrm{A}(\mathrm{H} 1 \mathrm{~N} 1)$ infection in Canada. JAMA 302: 1872-1879, 2009.

24. Arcavi L and Benowitz NL: Cigarette smoking and infection. Arch Intern Med 164: 2206-2216, 2004.

25. Shiley KT, Van Deerlin VM and Miller WT Jr: Chest CT features of community-acquired respiratory viral infections in adult inpatients with lower respiratory tract infections. J Thorac Imaging 25: 68-75, 2010.

26. Miller WT Jr, Mickus TJ, Barbosa E Jr, Mullin C, Van Deerlin VM and Shiley KT: CT of viral lower respiratory tract infections in adults: Comparison among viral organisms and between viral and bacterial infections. AJR Am J Roentgenol 197: 1088-1095, 2011.

27. Zarychanski R, Stuart TL, Kumar A, Doucette S, Elliott L, Kettner J and Plummer F: Correlates of severe disease in patients with 2009 pandemic influenza (H1N1) virus infection. CMJA 182: 257-264, 2010

28. Rodriguez A, Alvarez-Rocha L, Sirvent JM, Zaragoza R, Nieto M, Arenzana A, Luque P, Socías L, Martín M, Navarro D, et al: Recommendations of the infectious diseases work group (GTEI) of the spanish society of intensive and critical care medicine and coronary units (SEMICYUC) and the infections in critically Ill patients study group (GEIPC) of the spanish society of infectious diseases and clinical microbiology (SEIMC) for the diagnosis and treatment of influenza A/H1N1 in seriously ill adults admitted to the intensive care unit. Med Intensiva 36: 103-137, 2012 (In Spanish). 